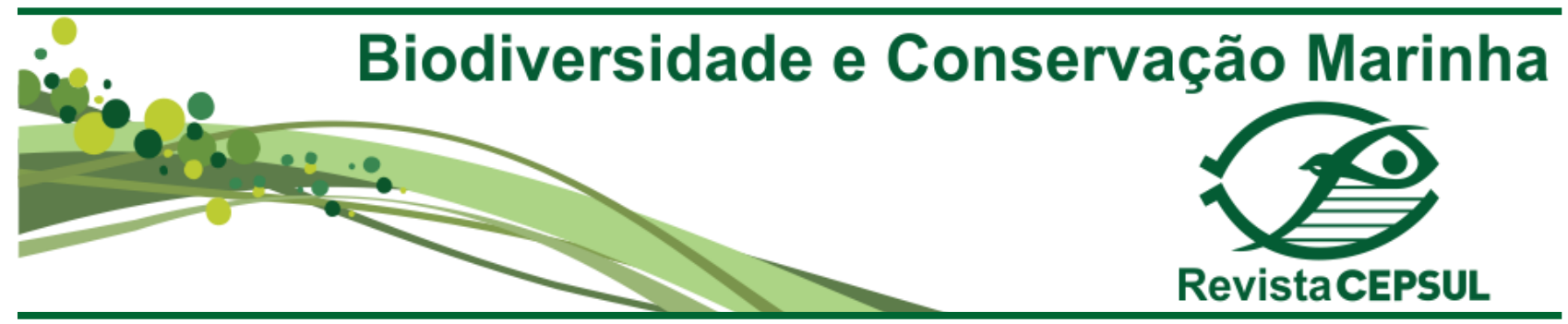

\title{
Lixo em áreas de nidificação de tartarugas-marinhas no litoral de Ipojuca/PE: uma breve avaliação e ações educativas
}

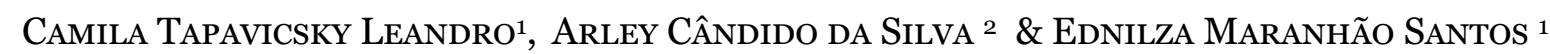

\begin{abstract}
1 Laboratório Interdisciplinar de Anfibios e Répteis, Departamento de Biologia, Universidade Federal Rural de PernambucoUFRPE, Rua Dom Manuel de Medeiros, s/n, CEP - 52171-9oo, Dois Irmãos, Recife, PE, Brasil, camilatsky@gmail.com, ednilzamaranhao@gmail.com;

2 ONG Ecoassociados, Rua Caraúna, s/n, Praça 4, CEP - 5559o-ooo, Porto de Galinhas, Ipojuca, PE, Brasil, ecoassociados.projeto@gmail.com.
\end{abstract}

Submetido em: 2o/11/2018; Aceito em: 13/o4/2021; Publicado em: 18/o5/2021

DOI 10.370o2/revistacepsul.vol1o.846e20210o4

Resumo. O presente trabalho teve como objetivo traçar um perfil do lixo encontrado nas praias de Merepe e Porto de Galinhas, litoral sul da cidade de Ipojuca, durante a temporada reprodutiva de tartarugas marinhas em 2016 (janeiro-abril). Foram feitas coletas mensais do lixo em 1,5 km de cada praia, sendo 18 coletas na praia de Merepe e cinco coletas na praia de Porto de Galinhas. Os resíduos encontrados nas áreas de desova de tartarugas foram triados, quantificados, categorizados, armazenados e utilizados em uma ação de sensibilização na comunidade de Porto de Galinhas. Um total de dez categorias e 27 subcategorias de resíduos fez parte da amostra, sendo "plástico" em maior quantidade. No geral o lixo das praias foi prioritariamente proveniente de descarte individual da população, como bitucas de cigarros, chinelos e sacolas. A ação de sensibilização visou alertar a população quanto aos impactos causados pelos resíduos sólidos antropogênicos às tartarugas na região litorânea de Merepe e Porto de Galinhas. A exposição "Lixo ao mar" aconteceu na sede da ONG Ecoassociados em Porto de Galinhas e no Colégio Assunção, localizado em Jaboatão dos Guararapes, Pernambuco. Cerca de 400 pessoas, entre crianças, adolescentes e adultos visitaram a exposição e puderam saber mais sobre as tartarugas marinhas, sobre lixo e seu descarte. A interação foi marcante nesse processo necessitando que essa ação se torne contínua em Porto de Galinhas.

Palavras-chave: resíduo sólido, sensibilização, plástico.

Abstract. Garbage in the areas of marine turtles' nidification in the coast of Ipojuca/PE: educational actions. The present work had as objective to trace a profile of the garbage found in the beaches of Merepe and Porto de Galinhas, south coast of the city of 
Ipojuca, during the reproductive season of sea turtles in 2016 (January-April). Monthly garbage collections were made at $1.5 \mathrm{~km}$ from each beach, with 18 collections at Merepe beach and five collections at Porto de Galinhas beach. The residues found in the turtle spawning areas were sorted, quantified, categorized, stored and used in an awareness campaign in the Porto de Galinhas community. A total of ten categories and 27 subcategories were part of the sample, with "plastic" being the residue in the greatest quantity. In general, the garbage on the beaches came primarily from individual disposal by the population, such as cigarette butts, slippers and bags. The sensitization action aimed to alert the population about the impacts caused by anthropogenic solid waste to turtles in the coastal region of Merepe and Porto de Galinhas. The exhibition "Lixo ao mar" took place at the headquarters of the NGO Ecoassociados in Porto de Galinhas and at Colégio Assunção, located in Jaboatão dos Guararapes, Pernambuco. About 400 people, including children, teenagers and adults visited the exhibition and were able to learn more about sea turtles, garbage and their disposal. The interaction was remarkable in this process, requiring this action to become continuous in Porto de Galinhas.

Keywords: solid waste, awareness, plastic.

\section{Introdução}

Historicamente os oceanos são considerados lixeiras das diferentes civilizações humanas. O Brasil apresenta cerca de $7.400 \mathrm{~km}$ de extensão de praia, as maiores metrópoles estão próximas ao oceano, sendo que $70 \%$ da população brasileira reside a não menos que $200 \mathrm{~km}$ do mar (Global Garbage, 2010). Uma boa parcela dessa população mora em situação de pobreza e não dispõe de rede de esgotos, nem de sistema de coleta de lixo. Essa população produz 56 mil toneladas diárias de lixo e aproximadamente 40 mil não são coletadas. $O$ lixo coletado vai para lixões a céu aberto ou outros tipos de aterros sanitários, muitos situados perto de rios, do mar ou de outro tipo de área de drenagem (Global Garbage, 2010).

Os oceanos e as zonas costeiras estão sendo afetados por várias ações antrópicas. Ao longo dos últimos anos, o impacto que mais se destaca é a poluição marinha por resíduos sólidos antropogênicos. Estes podem ser originados a partir de despejos de embarcações ou por deriva de outras praias, provenientes do continente, por meio da drenagem de esgoto em áreas próximas ou pelo descarte de lixo por frequentadores das praias (Granziera \& Gonçalves, 2012).

Para o controle da poluição em ambientes marinhos e costeiros é necessário que exista uma gestão ambiental responsável para o gerenciamento da zona costeira, e imprescindivelmente, a participação ativa da população para manter a integridade dessas áreas (Barbosa, 2013). O poder público tem realizado diferentes formas para educar a sociedade sobre questões ambientais por meio de ações de educação ambiental, coleta seletiva, como também por meio da punição daqueles que exercem atividades poluidoras na destinação dos resíduos sólidos (Arruda, 2015).

Nos ambientes marinhos e costeiros, os resíduos têm sido apontados como problemas para a manutenção da biota aquática. Um trabalho realizado por Laist (1997) avaliou que mais de 260 espécies de animais marinhos são afetadas pelo lixo, dentre essas as tartarugas marinhas. Durante a temporada reprodutiva, as tartarugas se aproximam da costa para desovar e se alimentar, aumentando o contato com regiões poluídas e acarretando ingestão de resíduos sólidos e restos de redes de pesca impedindo a locomoção, podendo levar as tartarugas marinhas ao óbito (Sanches, 1999). Vale ressaltar que todas as espécies de tartarugas marinhas se encontram em alguma categoria de ameaça de extinção (IUCN, 2015) devido a diversos tipos de impactos como, por exemplo, a poluição do ambiente marinho. Uma das metas do Plano de Ação Nacional (PAN) para a Conservação das Tartarugas Marinhas é a pro- 
moção de ações que envolvam a educação ambiental, com a realização de atividades que informem ao cidadão os impactos causados pelo lixo na biota marinha, em especial às tartarugas (ICMBio, 2017).

A ingestão dos resíduos sólidos pelas tartarugas marinhas ainda necessita de mais estudos, pode ocorrer quando elas os confundem com seu alimento natural ou quando acidentalmente os ingerem junto ao alimento, podendo causar a obstrução do trato digestivo, desencadeando em uma série de danos físicos e orgânicos, como a formação de fecalomas e ulcerações que podem ser letais (Laist, 1987, Sanches, 1999, Schuyler et al., 2012, 2014). Seis das sete espécies de tartarugas marinhas existentes no mundo já foram encontradas com resíduo sólido presente no conteúdo estomacal (Laist, 1997). O mesmo ocorre na costa brasileira, onde a quantidade de resíduos presentes vêm causando impactos à sobrevivência das tartarugas (Awabdi et al., 2013, Ormedilla et al., 2014).

O município de Ipojuca (Pernambuco) desenvolveu-se de forma rápida e desordenada e contava com uma população de 97.669 habitantes (IBGE, 2020). É composto por indústrias, distribuidoras de combustíveis, usinas de cana-de-açúcar, mas o desenvolvimento local é impulsionado pelo turismo (Simões et al., 2016). Porto de Galinhas recebe aproximadamente 65 mil turistas por mês, durante o período de alta estação que ocorre de novembro a março e em julho, e cerca de 10 mil durante a baixa estação, sendo $89 \%$ brasileiros e $11 \%$ estrangeiros (Ipojuca, 2008). O turismo no local movimenta cerca de $\mathrm{R} \$ 3$ milhões em impostos, que são investidos na manutenção da praia e em todo o seu território municipal (Lima, 2006).

As praias do município de Ipojuca são áreas de preferência para a desova de tartarugas marinhas. Todas elas apresentam características ambientais como temperatura, umidade, tipo de areia e topografia favoráveis à escolha do ambiente para a desova desses animais (Simões et al., 2014). Contudo, todas as praias sofrem influência direta de condomínios, hotéis e pousadas com turismo intenso na época da temporada (Simões et al., 2016). De acordo com dados da Prefeitura, sobre a coleta de lixo, 315 pessoas são responsáveis pela limpeza do município e nas áreas de praia. A limpeza também conta com 12 carros compactadores e os garis dividem-se em coleta, varrição e capinação, recolhendo cerca de 100 toneladas de lixo por dia (Ipojuca, 2008, 2014). A coleta do lixo é realizada três vezes ao dia, em horários estabelecidos e sempre é possível ver funcionários da prefeitura fazendo a limpeza de calçadas e ruas, porém, segundo moradores locais, essa prática não é observada por todos (Santos \& Cândido, 2015).

Com isso, esse trabalho teve como objetivo avaliar no período de maior atividade reprodutiva de tartarugas marinhas em 2016, o lixo encontrado nas praias de Merepe e Porto de Galinhas/Ipojuca, áreas de nidificação. O material coletado foi utilizado para uma exposição educativa em escolas e no museu das tartarugas em Porto de Galinhas.

\section{Material e métodos}

\section{Área de estudo}

A área de estudo está localizada no município de Ipojuca ( $08^{\circ} 24^{\prime} 06^{\prime \prime S}$ e $\left.35^{\circ} 03^{\prime} 45^{\prime \prime} \mathrm{W}\right)$, a $57 \mathrm{~km}$ de Recife. A praia de Merepe $\left(80^{\circ} 27^{\prime} 15^{\prime \prime S}\right.$ e $\left.34^{\circ} 59^{\prime} 52^{\prime \prime} \mathrm{W}\right)$ foi escolhida devido ao grande número de ninhos registrados (Moura et al., 2012). Tem 3,47 km de extensão e possui características favoráveis para postura de ninhos, pois não apresenta barreiras de corais, o que facilita o acesso das fêmeas à faixa de areia. A praia de Merepe está ligada à praia de Porto de Galinhas, mais visitada e um dos principais pontos turísticos do estado de Pernambuco, com 1,47 km de extensão. As praias apresentam trechos de vegetação litorânea e exótica e sofrem influência direta de hotéis, pousadas, casas e condomínios (Simões et al., 2014) (Figura 1).

\section{Coleta dos resíduos}

A obtenção de dados foi realizada no 


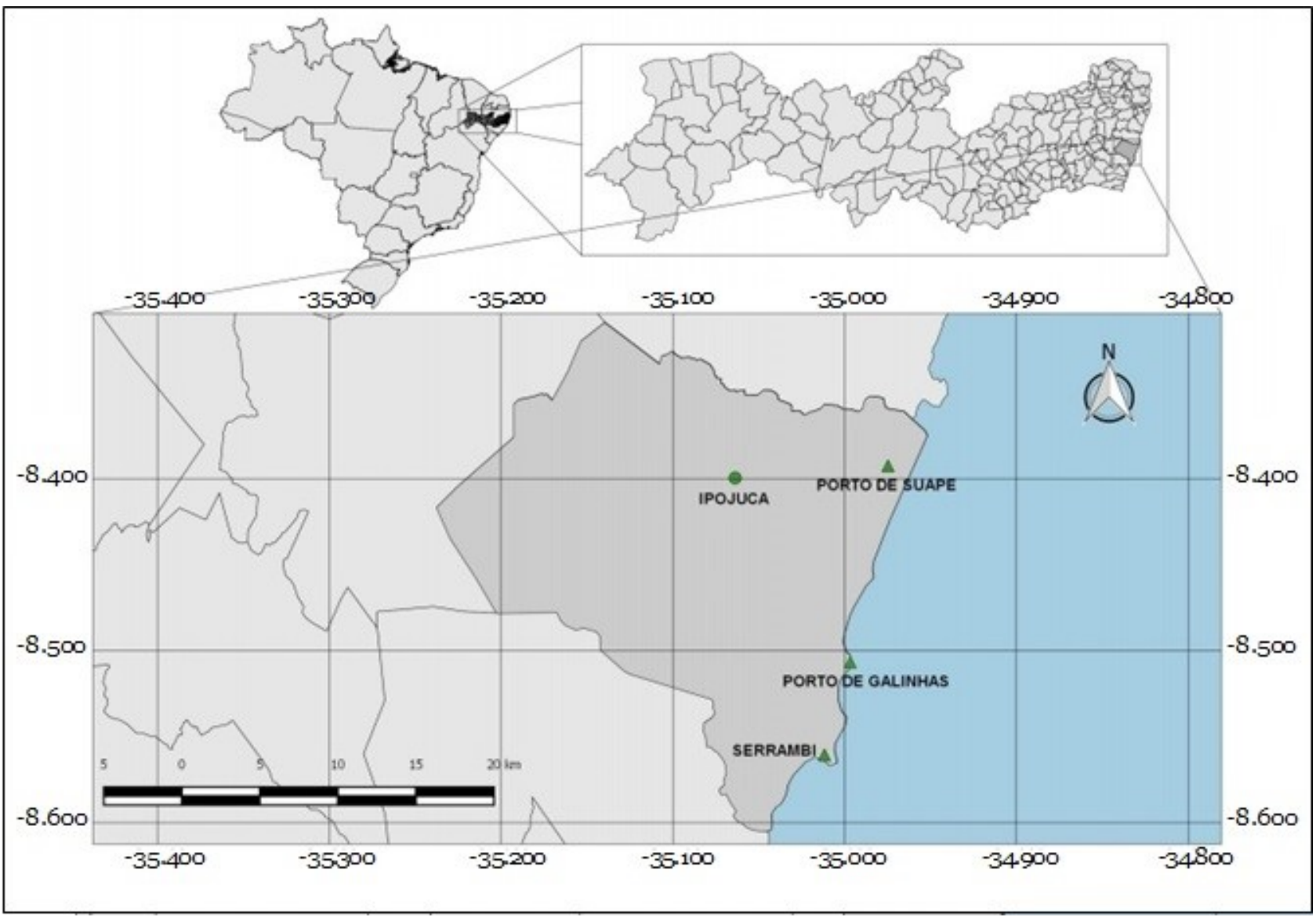

Figura 1. Mapa de localização da área de estudo, evidenciando as praias onde há nidificação de tartarugas e monitoradas pela ONG Ecoassociados. Fonte: Simões et al., 2014.

período de 30 de janeiro a 30 de abril, durante a temporada de 2016, nas praias de Merepe e Porto de Galinhas totalizando 23 dias de coleta, durante a maré secante e antes da coleta de lixo nas praias. Na praia de Merepe foram escolhidos dois pontos de coleta (ponto $1-8^{\circ}$ $29^{\prime} 47^{\prime \prime} 73^{\circ} \mathrm{S}$ e $35^{\circ} \mathrm{O}^{\prime} 10^{\prime \prime} 71^{\circ} \mathrm{O}$, ponto $2-8^{\circ}$

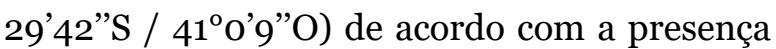
de ninhos no local, totalizando 18 coletas sendo nove em cada um dos pontos, realizados simultaneamente. Na praia de Porto de Galinhas apenas um ponto foi selecionado ( $8^{\circ} 30^{\prime} 11$ "s / $\left.41^{\circ} \mathrm{O}^{\prime} 4^{\prime \prime} \mathrm{O}\right)$ e cinco coletas foram realizadas neste local. O esforço foi menor em Porto de Galinhas devido à ausência de ninhos de tartaruga, todavia foi escolhido por se tratar da praia com maior volume de visitantes e maior número de bares e barracas.

Foi percorrido/vistoriado um transecto de $1,5 \mathrm{~km}$ de extensão a partir de cada ponto, por excursão realizada, em uma faixa de até 30 $\mathrm{m}$ de largura. As coletas foram realizadas ma- nualmente, por um indivíduo, durante o esforço de uma hora e meia. As amostras encontradas (Figura 2, A a D), foram depositadas em sacos de lixo de 100 L para serem triadas. Durante a triagem, as amostras foram colocadas para secar e, posteriormente, separadas e pesadas em balança de precisão (g). Com o auxílio de uma planilha de dados, todo o material triado e quantificado, foi categorizado e subcategorizado.

\section{Ação educativa - exposição "Lixo ao Mar"}

Os resíduos triados foram armazenados para compor o cenário e peças da exposição "Lixo ao mar". Os materiais utilizados para compor a exposição foram peças diversas, quadros montados utilizando pallets, imagens de tartarugas encontradas mortas (com lixo), adesivadas em folha de PVC de 1,5X1,5 m; quadros construídos com restos de lixo, banner em lona, 


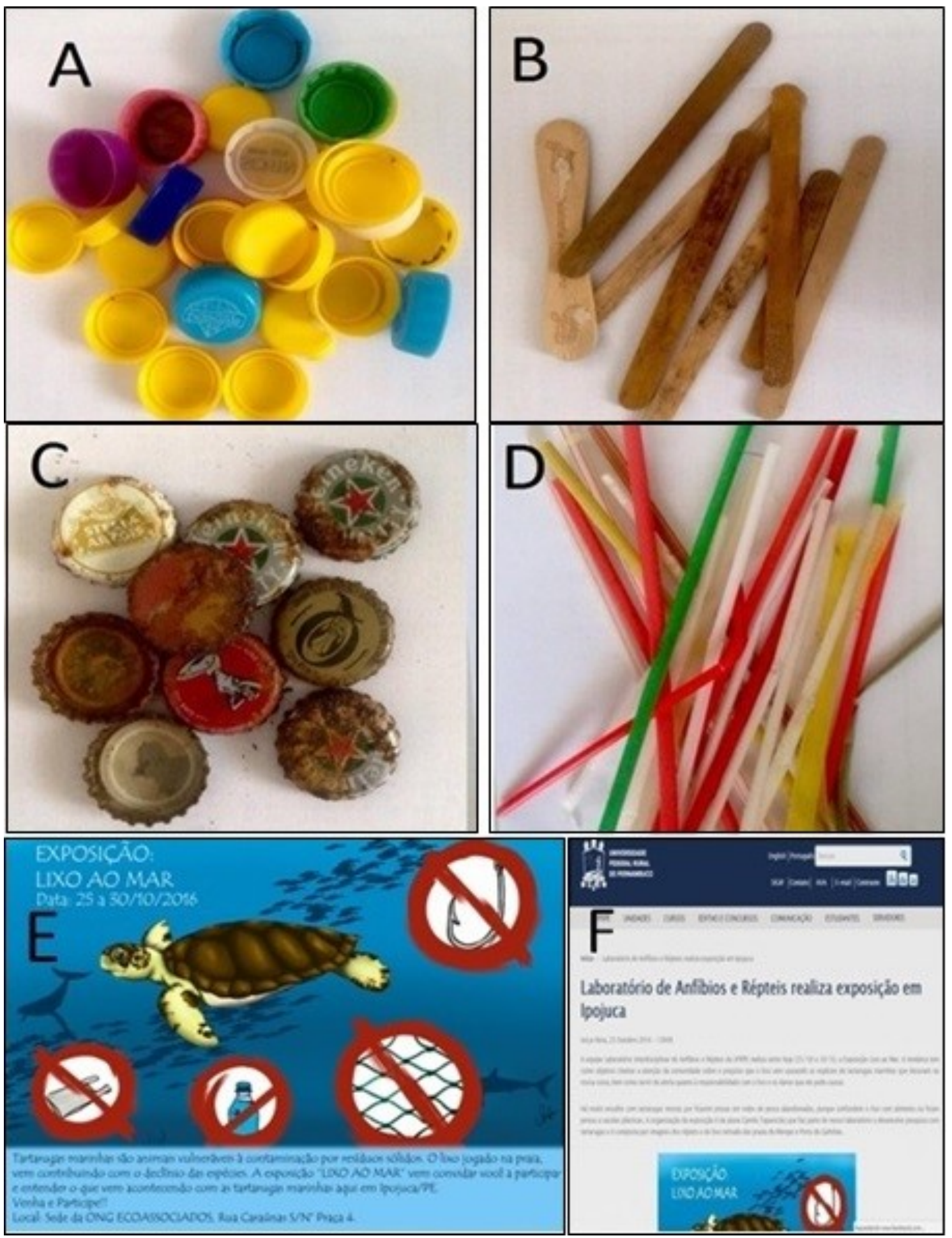

Figura 2. Amostra de alguns resíduos coletados na área de estudo, cartaz usado para divulgação nas escolas e universidades e divulgação por meio do site da Universidade Federal Rural de Pernambuco (UFRPE). A. Tampas plásticas. B. Palitos de picolé. C. Tampas de cerveja. D. Canudos. E. Cartaz. F. Site da UFRPE.

\section{informativos e cartazes.}

Para a realização da exposição "Lixo ao Mar” foram elaborados convites e cartazes que foram enviados às escolas municipais do entorno de Porto de Galinhas e Nossa Senhora do Ó, totalizando dez escolas convidadas (Figura 2E). Também foram convidadas as Universidades Federal e Federal Rural de Pernambuco. A divulgação também ocorreu através de mídias sociais, como Facebook, Instagram e na página 


\section{da UFRPE (Figura 2E).}

A exposição aconteceu na sede do Projeto Ecoassociados, localizada na Praia de Porto de Galinhas/Ipojuca, no período de 25 a 30 de outubro de 2016, durante o horário de expediente de seu museu (das 9:00 às 18:00 h), com visitas abertas ao público sem custo de entrada. Através de uma solicitação de um professor que visitou a exposição na Ecoassociados o acervo foi apresentado no Colégio Assunção, localizado na Barra de Jangada, município de Jaboatão dos Guararapes, no dia 01 de novembro de 2016. Durante o intervalo, crianças e adolescentes (de quatro a 15 anos de idade) da Educação Infantil ao nono ano do Ensino Fundamental também puderam conhecer um pouco mais sobre o descarte correto do lixo, a influência e o impacto do lixo nas praias, oceanos e como pode afetar as tartarugas marinhas (Figura 3). As interações durante a exposição ocorreram por meio de abordagem e apresentação da temática exposta.

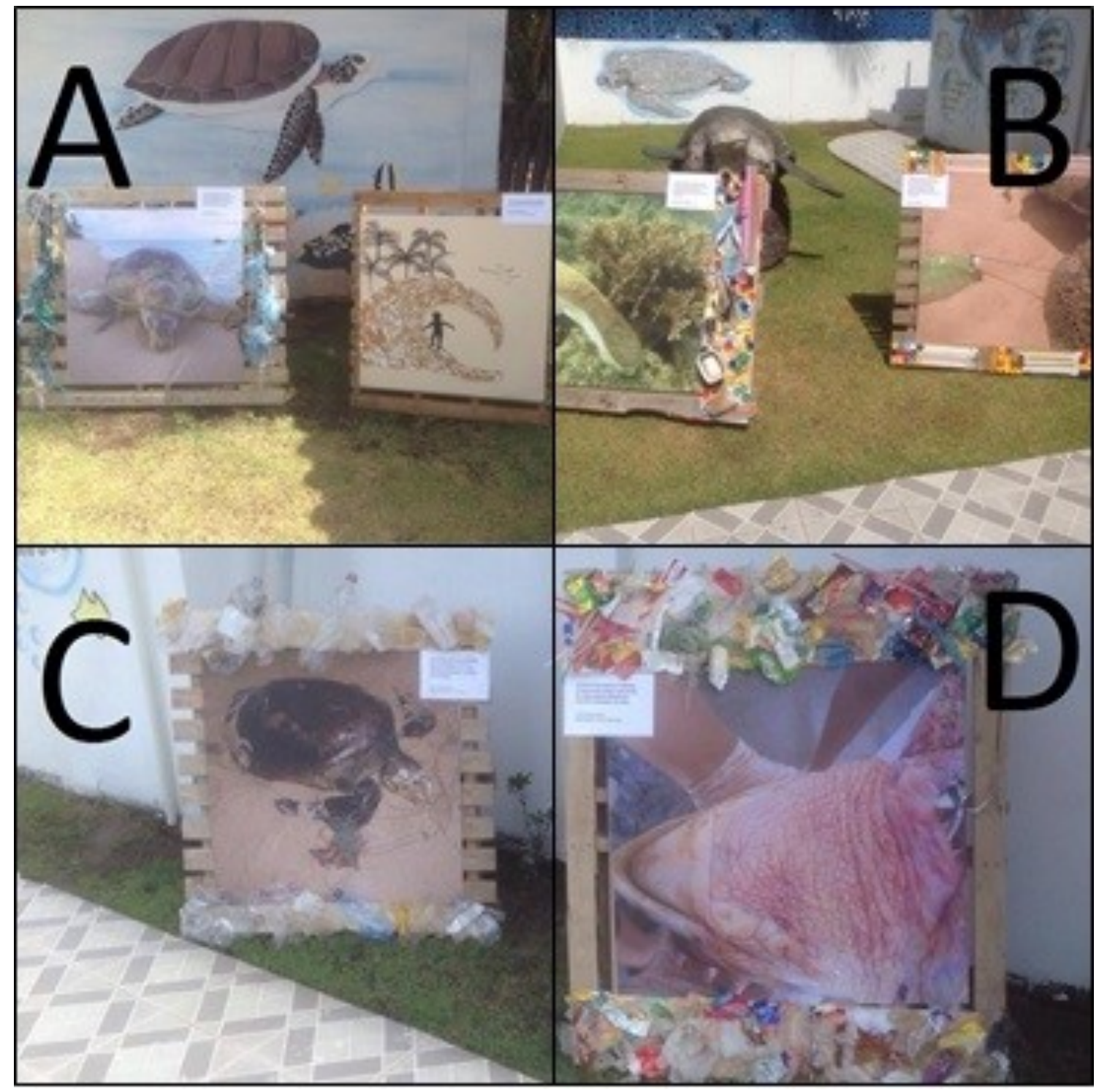

Figura 3. Pallets ornamentados com lixo encontrado na praia e imagens de tartarugas mortas devido ao lixo, utilizados como parte do acervo da Exposição "Lixo ao Mar". A. Imagem de Chelonia mydas emaranhada com um cabo. À direita, painel feito com bitucas de cigarro coletadas na praia. B. Imagem de sola de sapato junto ao recife de coral. À direita, imagem de tartaruga com a nadadeira estrangulada por um fio plástico preso a uma garrafa pet. C. Eretmochelys imbricata emaranhada em fio de nylon, com as nadadeiras estranguladas. D. Eretmochelys imbricata com um anzol preso no esôfago. Fonte imagens: Ecoassociados e Cláudio Sampaio. 


\section{Análise de dados}

Foi calculada a abundância, frequência relativa e absoluta de cada categoria e subcategoria de resíduo sólido, de modo que fosse determinada a mais expressiva, o percentual de cada uma delas, a massa e a variação quantitativa em cada ponto de coleta selecionado em cada praia, e o total dos resíduos sólidos acumulados no período de quatro meses. Utilizouse o teste do Qui-quadrado para avaliar diferenças nas amostras entre os meses.

\section{Resultados e discussão}

\section{A coleta do lixo em Merepe e Porto de Galinhas}

Foi possível identificar o total de nove categorias de resíduos encontrados nas praias, dentre esses, o plástico (86\%), outros ( $9 \%$ ) e madeira (2\%) foram as categorias mais expressivas (Figura 4, Tabela 1). O número de categorias foi bem similar ao apresentado por Sul
(2005), com exceção de Tetra pack e óleo bruto que não foram encontrados nas coletas. A categoria plástico foi a mais expressiva (em unidade e massa, Tabela 1) na amostra, o que corrobora com outros estudos em praias (Pianowski, 1997, Sul, 2005, Mascarenhas et al., 2008, Bruno \& Santos, 2011, Barbosa, 2013, Orlandi et al., 2015) e é o que mais se destaca nas análises de conteúdo nos estômagos das tartarugas (Laist, 1987, Reis et al., 2010, Awabdi et al. 2013, Ormedilla et al., 2014).

O plástico é conhecido por ser um dos principais resíduos sólidos no ambiente marinho. O desenvolvimento econômico e tecnológico, principalmente nos últimos cinquenta anos, e a indústria avançou para a produção de materiais baratos, leves, maleáveis e duráveis. Por serem bastante acessíveis à toda população e práticos, os plásticos tornaram-se dispensáveis, ou seja, são facilmente descartados. Todavia, levam muitos anos para se decompor, permanecendo por longos períodos no ambiente, acumulando os seus resíduos e se dispersando em toda a costa e áreas oceânicas. Plásticos são compostos orgânicos sintéticos emergentes que

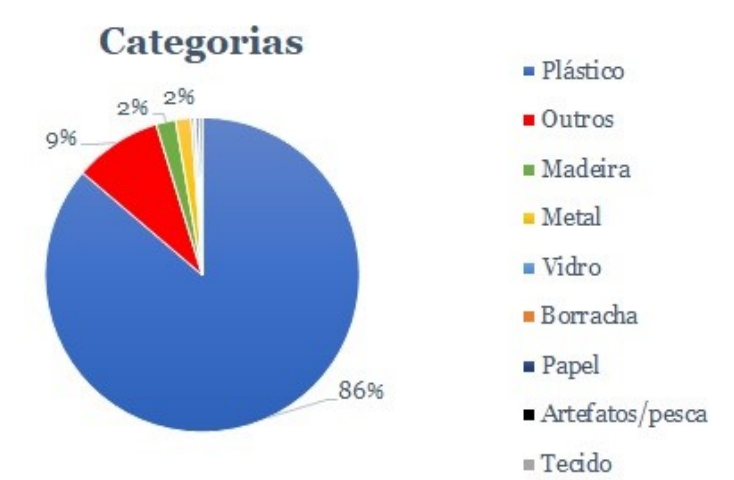

\section{A - Categoria plástico}
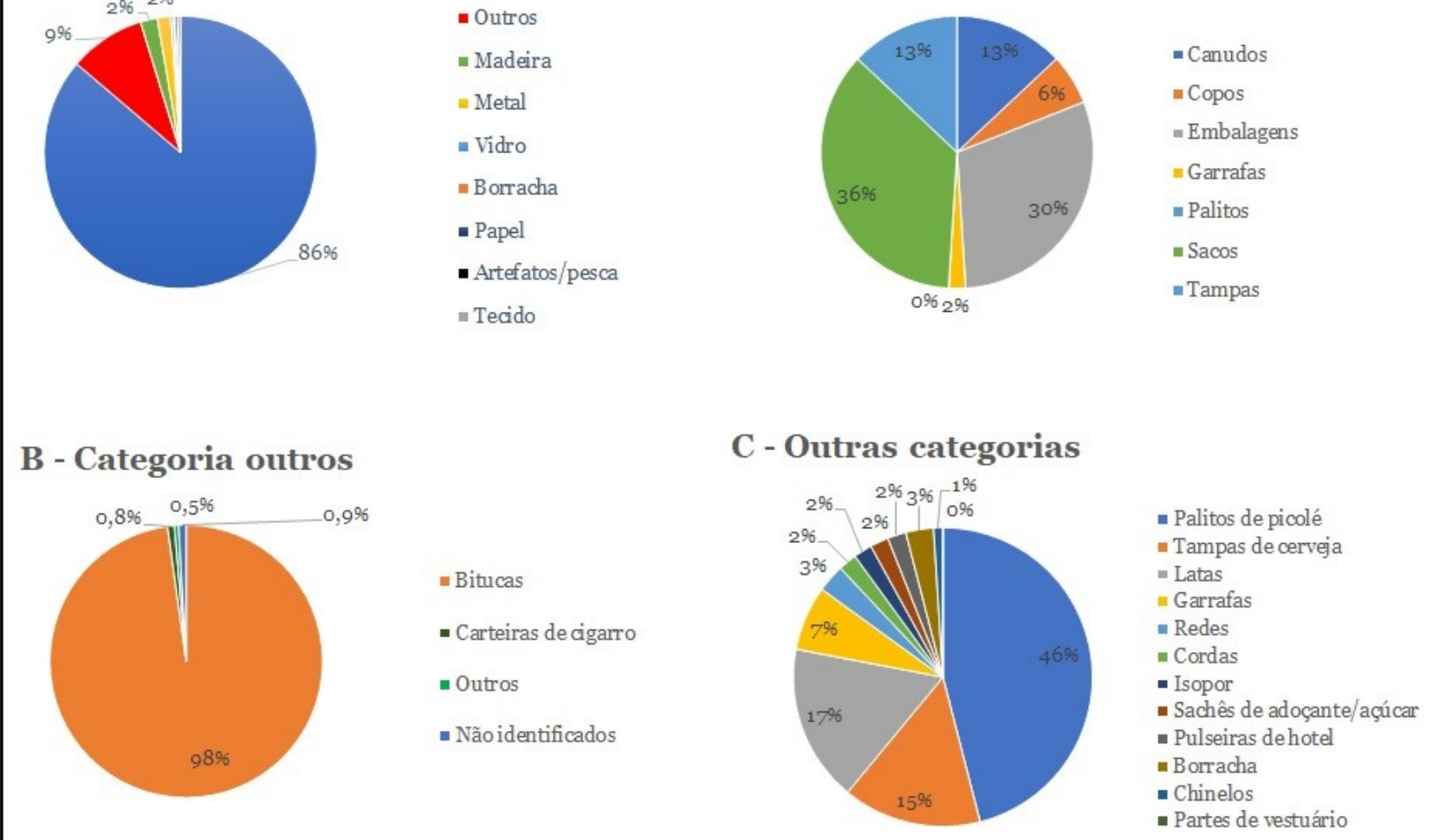

Figura 4. Frequência relativa das categorias e subcategorias referente aos resíduos encontrados nas praias de Porto de Galinhas e Merepe/Ipojuca-PE, durante o período janeiro a abril de 2016. A. Categoria plástico. B. Categoria outros. C. Outras categorias. 
Tabela 1. Categorias dos itens relacionados aos resíduos sólidos coletados nas praias de Porto de Galinhas e Merepe, durante janeiro a abril, 2016, com suas respectivas informações quanto ao uso, quantidade, massa e subcategorias.

\begin{tabular}{|c|c|c|c|c|c|}
\hline Categorias & Usos & Unid. & Massa (kg) & Subcategorias & $\mathbf{N}$ \\
\hline \multirow{7}{*}{ Plástico } & \multirow{7}{*}{$\begin{array}{l}\text { Doméstico, } \\
\text { pesca, } \\
\text { higiene }\end{array}$} & \multirow{7}{*}{7.601} & \multirow{7}{*}{3,877} & Garrafas pet & 154 \\
\hline & & & & Copos & 423 \\
\hline & & & & Embalagens & 2.309 \\
\hline & & & & Sacos & 2.700 \\
\hline & & & & Canudos & 989 \\
\hline & & & & Palitos de picolé & 17 \\
\hline & & & & Tampas & 1.009 \\
\hline \multirow{2}{*}{ Papel } & \multirow{2}{*}{$\begin{array}{l}\text { Alimentação, } \\
\text { lazer }\end{array}$} & \multirow{2}{*}{23} & \multirow{2}{*}{0,085} & $\begin{array}{l}\text { Pulseiras de acesso a } \\
\text { hotéis }\end{array}$ & 11 \\
\hline & & & & $\begin{array}{l}\text { Embalagem de ado- } \\
\text { çante e açúcar }\end{array}$ & 12 \\
\hline \multirow[b]{2}{*}{ Metal } & \multirow[b]{2}{*}{ Alimentação } & \multirow[b]{2}{*}{145} & \multirow[b]{2}{*}{0.665} & Tampas de cerveja & 69 \\
\hline & & & & $\begin{array}{l}\text { Alumínio/latas de } \\
\text { bebidas }\end{array}$ & 76 \\
\hline $\begin{array}{l}\text { Artefatos de } \\
\text { pesca }\end{array}$ & $\begin{array}{c}\text { Pesca, } \\
\text { embarcações }\end{array}$ & 19 & 0,322 & $\begin{array}{l}\text { Fragmentos de re- } \\
\text { des de pesca, linhas } \\
\text { e cordas }\end{array}$ & 19 \\
\hline \multirow{2}{*}{ Madeira } & \multirow{2}{*}{$\begin{array}{l}\text { Alimentação, } \\
\text { doméstico }\end{array}$} & \multirow{2}{*}{206} & \multirow{2}{*}{0,398} & Palitos de picolé & 205 \\
\hline & & & & Pegador de roupa & 1 \\
\hline \multirow[t]{2}{*}{ Borracha } & \multirow{2}{*}{$\begin{array}{l}\text { Vestuário, } \\
\text { lazer }\end{array}$} & \multirow{2}{*}{21} & \multirow{2}{*}{0,736} & Bexigas de festa & 15 \\
\hline & & & & Chinelos & 6 \\
\hline Vidro & Alimentação & 30 & 7.109 & $\begin{array}{l}\text { Garrafas de cerveja, } \\
\text { vinho e tempero }\end{array}$ & 30 \\
\hline Isopor & $\begin{array}{c}\text { Boias, } \\
\text { embarcações }\end{array}$ & 7 & 0,008 & Fragmentos & 7 \\
\hline Tecido & Vestuário & 2 & 0,056 & Parte de vestuário & 2 \\
\hline \multirow{7}{*}{ Outros } & \multirow{7}{*}{$\begin{array}{l}\text { Doméstico, } \\
\text { lazer, } \\
\text { alimentação }\end{array}$} & \multirow{7}{*}{779} & \multirow{7}{*}{0,101} & Filtros de cigarro & 762 \\
\hline & & & & Carteiras de cigarro & 6 \\
\hline & & & & Rodo de limpeza & 1 \\
\hline & & & & Isqueiro & 1 \\
\hline & & & & Enfeite natalino & 1 \\
\hline & & & & Rolha & 1 \\
\hline & & & & Não identificado & 7 \\
\hline
\end{tabular}


adsorvem substâncias químicas tóxicas, categorizadas como poluentes orgânicos persistentes (POPs), que se acumulam no ambiente e geram bioacumulação nos seres vivos. Os danos destes compostos à fauna podem levar à bioacumulação em tecidos, deficiência de sistema imune, alterações no sistema endócrino, carcinogenia e mutagenia (Araújo \& Costa, 2003, Yoshida, 2012).

Na categoria "outros", a segunda maior em número, composta seis subcategorias, o destaque para filtros de cigarros, evidencia a prática comum dos fumantes em jogar esse item na praia, sem colocá-los em lixeiras. Medidas devem ser tomadas como educação ambiental e prática de destino correto desse resíduo. Soluções adequadas devem ser identificadas para o manejo dos resíduos descartados, bem como para o seu transporte e acondicionamento, além do aumento da frequência de coletas de lixo. De uma maneira geral, os itens encontrados nas praias são comuns na região e a maioria é comumente descartada pelos banhistas, evidenciando a necessidade de uma ação educativa mais eficiente e contínua nas praias.

Plástico foi a categoria com mais subcategorias $(n=10)$, seguida de outros $(n=6)$ (Tabela 1 e 2), isso mostra a variedade de uso desse elemento e por disso a maior quantidade desse resíduo. Entre os usos, o doméstico se destaca, seguido de nylon para rede de pesca (Tabela 2). O material usado como rede de pesca e que é descartado nos oceanos é um dos resíduos que mais provoca a mortalidade de organismos marinhos incluindo as tartarugas marinhas, processo conhecido como pesca fantasma, que causa estrangulamento e morte por ingestão (Schneider, 2009, World Animal Protection, 2018), todavia não foi um item muito evidente nas amostras. Contudo, deve-se ressaltar que outras áreas devem ser monitoradas no litoral para uma maior avaliação. Segundo o estudo de Sales et al. (2003), com bases nas informações dos pescadores as tartarugas trazem prejuízos para a pesca devido a danos aos petrechos utilizados.

Quanto às subcategorias, os sacos plásticos apresentaram maior ocorrência, totalizando 2.700 itens. As embalagens plásticas e as tampas de garrafas também mostraram um volume significativo, com 2.309 e 1.009 itens, respectivamente. No total, a categoria plástico teve uma massa de $3,877 \mathrm{~kg}$. A maior massa foi registrada na categoria vidro, com 7,109 $\mathrm{kg}$ e 30 itens de garrafas de cerveja, vinho e molho de temperos. Na categoria madeira, 205 itens foram contabilizados na subcategoria palitos de picolé, com 0,398 kg de massa. Foram registradas 69 tampas de cerveja de metal e 79 latas de alumínio de cerveja e refrigerante, somando 148 itens para a categoria metal e uma massa de $0,665 \mathrm{~kg}$. As categorias isopor $(\mathrm{n}=7)$ e tecido $(n=2)$ foram as menos expressivas (Tabela 1$)$.

Porém as categorias e subcategorias principais foram iguais. A categoria "plástico" foi a de maior destaque nas duas praias (Tabela 2), e em todos os pontos de coleta, sendo os sacos plásticos, a subcategoria principal. Segundo Sul (2005) mesmo com metodologias e esforços de coleta diferentes, a categoria plástico sempre é a mais frequente e em maior quantidade nas areias das praias, bem como nos oceanos. A praia de Merepe teve um total de

Tabela 2. Comparativo dos resíduos sólidos, geral e entre as praias de Merepe e Porto de Galinhas/Ipojuca -PE, durante janeiro a abril de 2016, destacando as categorias e subcategorias mais frequentes entre os pontos amostrados.

\begin{tabular}{lccccc}
\hline Dados & & Merepe & & \multicolumn{2}{c}{ Porto de Galinhas } \\
\hline Dados Gerais & Total & Ponto 1 & Ponto 2 & Total & P1 \\
\hline Número de categorias & 12 & 12 & 12 & 12 & 12 \\
Número de subcategorias & 25 & 25 & 25 & 25 & 25 \\
Categoria mais frequente & - & Plástico & Plástico & - & Plástico \\
Subcategoria mais frequente & 2216 & $\begin{array}{c}\text { Sacos } \\
\text { plásticos }\end{array}$ & $\begin{array}{c}\text { Sacos } \\
\text { plásticos }\end{array}$ & 484 & $\begin{array}{c}\text { Sacos } \\
\text { plásticos }\end{array}$
\end{tabular}


2.216 itens sacos plásticos, sendo 1.171 itens no ponto 1 e 1.045 sacos plásticos no ponto 2 . Em Porto de Galinhas, 484 itens sacos plásticos foram contabilizados no ponto único de coleta. No total, 1.527 itens de material não degradável foram encontrados na praia de Porto de Galinhas em cinco coletas efetuadas. Enquanto que na praia de Merepe foram registrados 7.288 itens, em um esforço de 18 coletas durante janeiro, fevereiro e março nas duas localidades.

As categorias documentadas nesse trabalho estiveram presentes em todos os meses de coleta, considerando uma análise geral (Figura 5), porém foi possível registrar que houve diferenças significativas entre o total de amostras e os meses estudados $\left(X^{2}=166175\right.$; $\mathrm{p}=0.000)$. "Plástico" e "outros" foram os itens de maior destaque, mas principalmente em março para a categoria "plástico" e fevereiro para categoria "outros". Possivelmente esse maior acúmulo de plástico e outros, nesses meses possa estar associado à ausência ou parcialidade da coleta seletiva do lixo para aquela data e mês. Concomitantemente deve ter ocorrido uma força tarefa maior da prefeitura nos serviços de limpeza de praia, o que é bem interessante. Nesse trabalho traçamos um perfil do lixo coletado evidenciando que se trata de lixo local proveniente do comércio de ambulante e do próprio turista, o que deixa claro a necessidade de ações de educação ambiental.

\section{A exposição "Lixo ao Mar"}

Durante a exposição no Projeto Ecoassociados, 135 alunos do nono ano da Escola Municipal Mário Julho do Rêgo, localizado em Nossa Senhora do Ó, e outros 221 visitantes passaram pela exposição Lixo ao Mar, totalizando 356 visitantes (Figura 6).

No Colégio Assunção, crianças e adolescentes da educação infantil ao nono ano puderam conhecer um pouco mais sobre o descarte correto do lixo, a influência e impacto do lixo nas praias, oceanos e como ele pode afetar as tartarugas marinhas.

Um fato que não pode deixar de ser comentado é o porquê apenas uma escola ter visi-

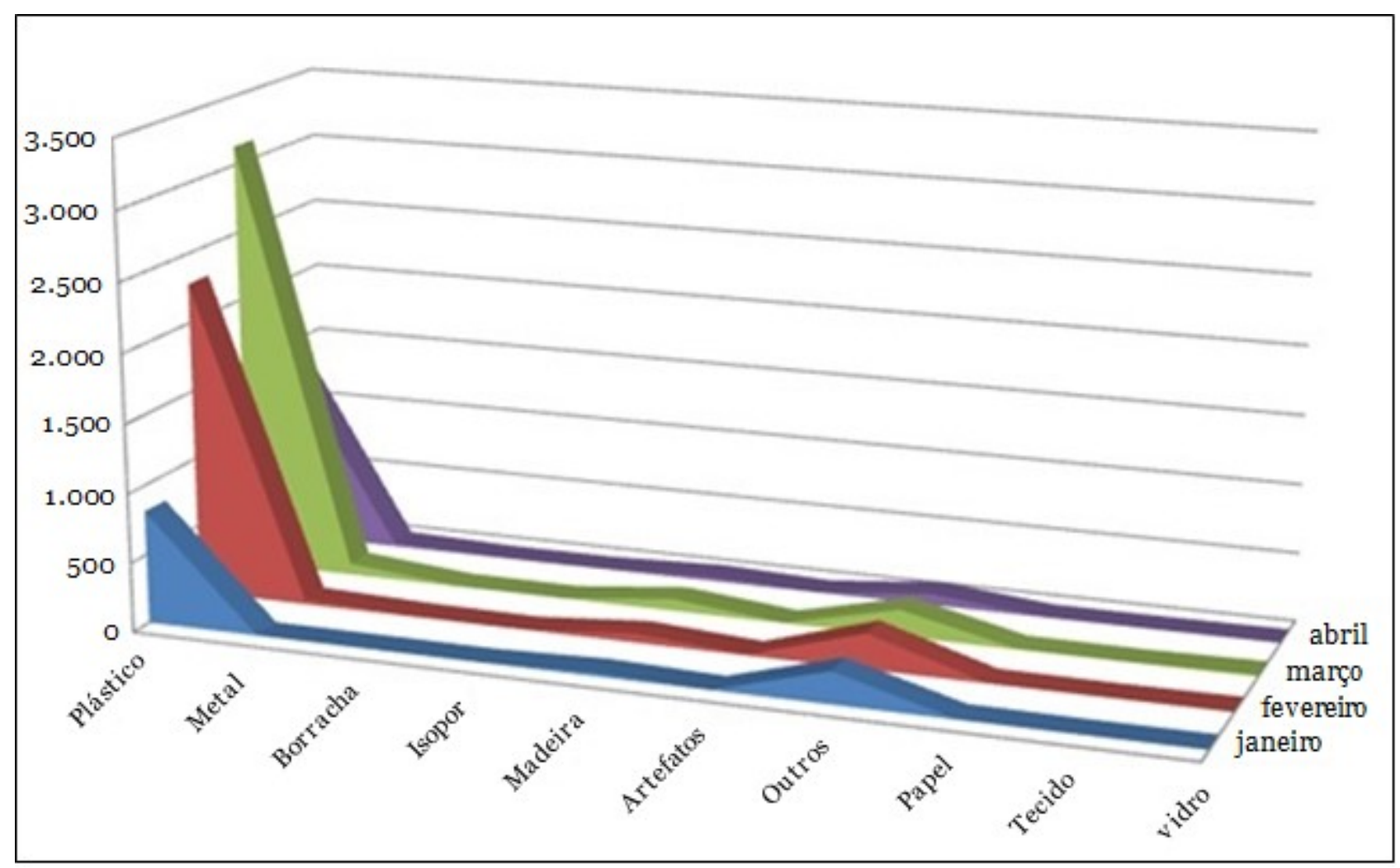

Figura 5. Frequência numérica das categorias referente aos resíduos sólidos encontrados nas praias de Merepe e Porto de Galinhas /Ipojuca, entre janeiro, fevereiro, março e abril 2016. 


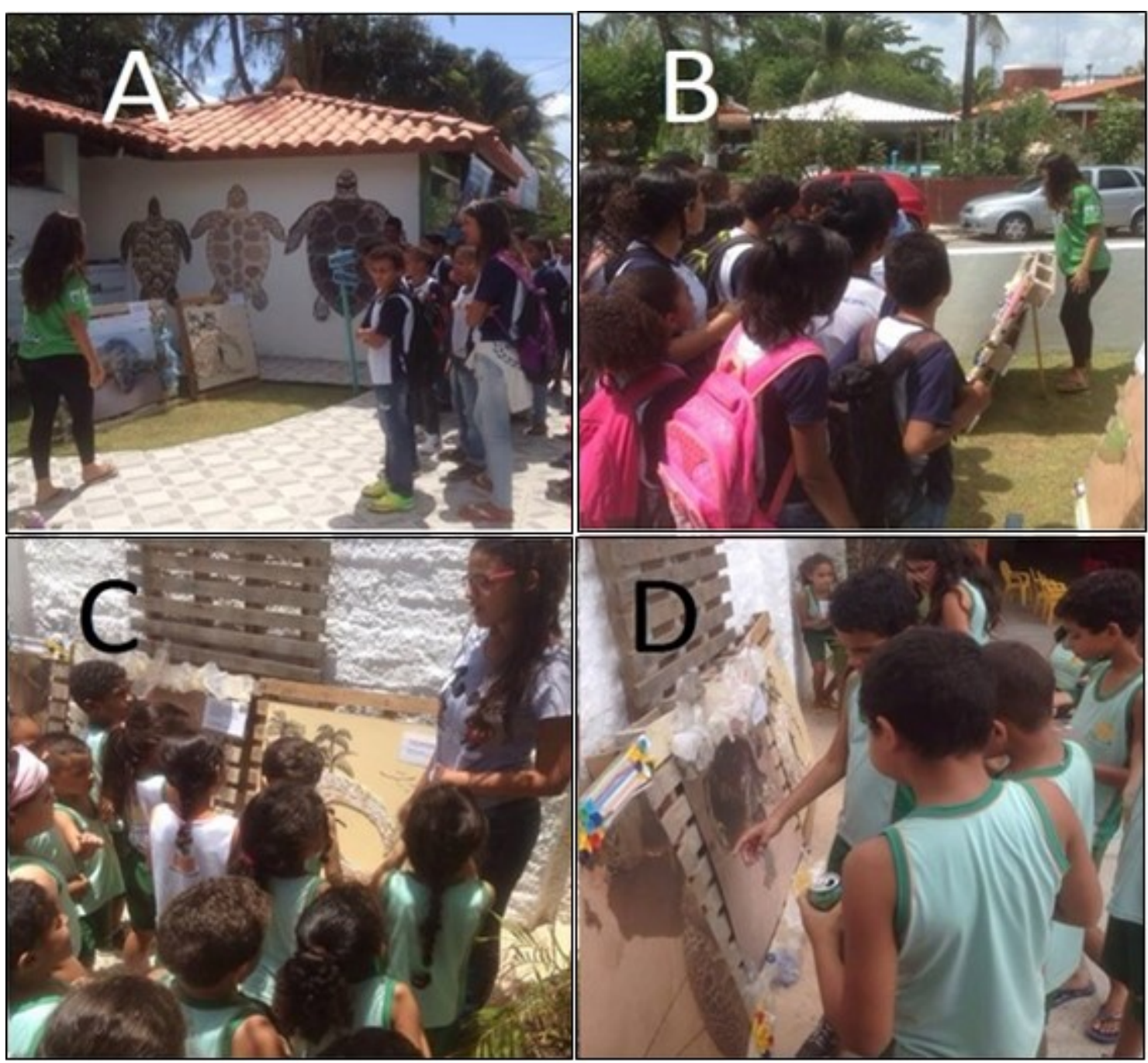

Figura 6. Primeiro dia da Exposição "Lixo ao mar" no projeto Ecoassociados/ Ipojuca-PE, 25/10/2016, recebendo a visita da Escola Mário Julho do Rêgo (A-B). Dia da exposição no Colégio Assunção, 01/11/2016 (C-D).

tado a sede da Ecoassociados na semana de exposição temática.

Uma das possibilidades está relacionada à disponibilidade da escola em transportar as crianças até o local, a disponibilidade de inserir como uma ação pedagógica no seu cronograma, como também a do seu professor. O que desperta a necessidade de um trabalho da ONG mais presente dentro das escolas, ou seja, que as ações de educação ambiental possam ser desenvolvidas em parceria. Se possível, incluídas no projeto político-pedagógico da instituição de ensino. Em algumas escolas o lixo vem sendo trabalhado, mas ainda de forma pontual, sem relação com as tartarugas.

Em 2014, Souza et al. (2015.), realizaram uma atividade em uma escola próxima a
Ecoassociados, onde houve atividade dentro da unidade de ensino e, posteriormente, os alunos foram até a ONG conhecer as atividades realizadas lá. Esses mesmos autores perceberam uma maior interação da escola e participação efetiva dos alunos. Durante essa ação desenvolvida por esses autores, foi possível observar a falta de conhecimento da comunidade sobre o trabalho da ONG, bem como sobre a importância do litoral ipojucano no ciclo de vida das tartarugas. Por isso é fundamental o estímulo de empoderamento das crianças sobre o local que residem e a necessidade da escola em trazer questões do cotidiano dos alunos para se discutir em sala de aula. Com base no que norteia os Parâmetros Curriculares Nacionais (PCN), a escola deve evidenciar os conteúdos teóricos e práticos para estimular a formação do cidadão 
(ME, 2001). Segundo Jacobi (2003, 2006), ao nos referirmos à Educação Ambiental, situamos em um contexto mais amplo, o da educação para a cidadania.

A valorização dos espaços não formais na formação dos estudantes também deve ser alvo de interesse das escolas, é quando se consegue trabalhar melhor alguns conteúdos, estratégia já evidenciada nos PCNs (ME, 2001). Jacobi (2003, 2006), define espaço para educação não formal como todo aquele onde pode ocorrer uma prática educativa, fora da escola. Há dois tipos de espaços não formais: os institucionalizados, que dispõe de planejamento, estrutura física e monitores qualificados para a prática educativa dentro deste local; e os espaços não institucionalizados que não dispõem de uma estrutura preparada para este fim, mas não significa que não podem ter ações educativas. Para esse último é necessário um planejamento, com isso, poderá se tornar um excelente espaço educativo. A Ecoassociados é um espaço para educação não formal institucionalizado, realizando uma prática de educação ambiental há mais de dez anos e que tem o objetivo de fortalecer a conservação de tartarugas marinhas, sendo necessário uma maior articulação entre as escolas e que as mesmas possam valorizar mais esses locais fora da sala de aula e próximos à escola.

Mesmo alcançando um número pequeno de escolas, o número de alunos e visitantes foi importante para perceber como ações como essa fazem a diferença e precisam ser de fluxo contínuo, como na fala de uma aluna:

“...nunca pensei que se tinha tanto tipo de lixo nessa praia” A1

Foi percebido certo espanto dos visitantes com a quantidade e os diferentes tipos de lixo exposto, a maioria de resíduos pessoais/ individuais como, chinelos, latas de refrigerante e bitucas de cigarros, ficando evidente que a situação é provocada por cada um que descarta seu lixo no próprio ambiente. Notou-se a presença de lixeiras nas calçadas das praias, mas é incipiente diante do fluxo de turistas que as visitam e isso é mais evidente em Porto de Galinhas. Alguns visitantes destacaram a exposição como importante, sugerindo que esta fosse realizada na praia para proporcionar o despertar de consciência em mais pessoas, principalmente os turistas, como disse uma senhora:

"Essa exposição deveria ser colocada lá na praia mesmo, iria causar mais impacto, pra todo mundo ver!" E2

Considera-se a sugestão de ações na praia viável e necessária (Suassuna, 2004), todavia uma das possibilidades discutidas no planejamento da exposição foi de possibilitar ao visitante o conhecimento sobre a ONG Ecoassociados, que vem há mais de uma década realizando trabalho com tartarugas e sendo uma das principais autoras na defesa do meio ambiente em Ipojuca.

A exposição teve como objetivo despertar uma reflexão sobre o lixo na praia e o que ele pode causar às tartarugas marinhas. Foi possível observar que as crianças se questionavam sobre a quantidade do lixo e o que eles causavam aos animais. As imagens de tartarugas mortas foram estimuladoras para essa reflexão, como o comentário da aluna de nove anos:

"Um copinho plástico não faz muita diferença, mas quinze copinhos já fazem".

Outra aluna, de sete anos, falou:

"É muito importante esse trabalho da senhora”.

Todas essas falas evidenciaram a relevância da Educação Ambiental que está pautada em uma interdisciplinaridade (Reigota, 2010). De acordo com os Parâmetros Curriculares Nacionais, o Meio Ambiente deve ser tratado como tema transversal, como forma de contemplar sua complexidade, sem restringi-la à abordagem de uma única área. Adotando essa perspectiva, as problemáticas sociais devem ser integradoras (Brasil, 1997). A problemática "lixo" deve fazer parte do projeto pedagógico da escola, inserida no contexto local. Nesse caso a morte de tartarugas marinhas ameaçadas de extinção encontradas nas praias de Merepe e Porto de Galinhas e o lixo são temas que preci- 
sam ser discutidos nas escolas da comunidade (Suassuna, 2004).

Durante os meses de verão, entre setembro e janeiro, ocorre o fluxo intenso de visitantes/veranistas no litoral de Ipojuca, sobreposto ao início de temporada de reprodução das tartarugas (Simões et al., 2016), período no qual as ações de educação devem ser mais intensas. A ONG Ecoassociados realiza atividades de monitoramento de tartarugas há mais de 10 anos em Ipojuca e, paralelamente, promove ações de educação ambiental, por meio de visitas guiadas pelos monitores voluntários ao acervo na sede da ONG. Todavia, a instituição entende que deve fazer parte também do acervo questões problematizadoras que impulsionem o visitante a refletir sobre a necessidade de mudar determinadas práticas para melhor viver no planeta. De uma maneira geral as práticas de Educação ambiental, mesmo que pontuais, vêm influenciando sobre a vida cotidiana do mundo atual, mas de forma menos decisiva do que o necessário (Mendonça, 2007), sendo indispensável a permanência e a continuidade dessa prática no litoral de Ipojuca (Souza et al., 2015).

Algumas iniciativas vem sendo realizadas, mesmo de forma pontual, com o objetivo de monitorar o problema e buscar possibilidade de melhorar ou de obter soluções (wwww.globalgarbage.org). Um marco importante é a Convenção das Nações Unidas sobre o Direito do Mar (CNUDM) aprovada no Brasil pelo Decreto Legislativo $\mathrm{n}^{\circ}$ 05, de 09 de setembro de 1987 (ONU, 2008), que destaca a problemática do lixo. Outras iniciativas em forma de lei é a legislação sobre a proibição de canudos plásticos, no Brasil há cerca de 160 cidades com essa legislação (Mailes Neto, 2019), no entanto para o estado de Pernambuco apenas Fernando de Noronha conquistou um decreto distrital 002/18 (Fernando de Noronha, 2018). Todavia Pernambuco, no seu plano de resíduos sólidos para a região metropolitana, que inclui uma bom número de cidades litorâneas, tem no tópico lixo marinho metas que priorizam a educação ambiental como ação necessária para minimizar os impactos ambientais (Pernambuco, 2018).

\section{Considerações finais}

A atividade antropogênica é a maior causa de impactos negativos ao meio ambiente e, de todo o lixo jogado no ambiente marinho, o plástico é o que aparece em maior escala. Os danos deste composto à fauna podem levar à bioacumulação em tecidos, deficiência de sistema imune, alterações no sistema endócrino, carcinogênica e mutagênica. Ainda, os animais podem sofrer emaranhamento e a sua ingestão pode levar ao sufocamento e obstrução do trato digestório. Tudo isso por conta da falta de atitude individual do homem. Há necessidade de ações educativas contínuas e mais vontade política no plano diretor que envolva no município a educação, meio ambiente e obras, e que todas as secretarias que fazem parte da gestão do município possam ter ações integradoras, trabalhando em sintonia para minimizar os problemas ambientais e sociais. Concomitantemente políticas públicas devem surgir para diminuir o plástico como o Projeto de Lei no 1691 de 2015, publicado no Diário Oficial do município de Ipojuca que visa proibir o uso de canudos plásticos. Todavia consideramos que a educação ambiental deve ocorrer em todos espaços, a fim de sensibilizar as pessoas quanto à necessidade da diminuição do uso de plástico e descarte inadequado dos resíduos.

Para desenvolver um trabalho sobre educação ambiental, abordando o tema tartarugas marinhas e o ambiente marinho, faz-se necessário elaborar métodos para que professores gestores incorporem no seu projeto político pedagógico essas opções. Bem como que valorizem os espaços para educação não formal, como é o caso da sede da Ecoassociados. Ações envolvendo campanhas de limpeza de praias devem ser estimuladas junto aos banhistas e à comunidade local e pescadores que descartam emaranhados de redes e anzóis no ambiente. Práticas devem ser estabelecidas de maneira integrada entre municípios vizinhos, proprietários de hotéis e pousadas com o intuito de minimizar a poluição em grandes áreas costeiras.

\section{Agradecimento}

Agradecemos a Ecoassociados e ao pro- 
fessor Cláudio Sampaio pelo apoio e as imagens cedidas para compor a exposição, bem como a todos os professores e alunos que visitaram e prestigiaram a Exposição.

\section{Referências Bibliográficas}

ARAÚJO, M. C. B \& COSTA, M. F. 2003. Lixo no ambiente marinho. Ciência Hoje, 32: 64-67.

ARRUDA, M. F. A. 2015. Análise da Aplicação da Política Nacional de Resíduos Sólidos nos Municípios do Litoral Pernambucano pertencentes à Região Metropolitana do Recife. 81p. (Dissertação de Mestrado. Programa de PósGraduação em Desenvolvimento e Meio Ambiente, UFPE).

AWABDI, D. R., SICILIANO, S. \& DI BEREDITTO, A. P. M. 2013. Ingestão de resíduos sólidos por tartarugas-verdes juvenis, Chelonia mydas (L. 1758), na costa leste do estado do Rio de Janeiro, Brasil. Biotemas, 26: 197-200.

BARBOSA, H. S. 2013. Classificação do lixo presente em área de reprodução de tartarugas marinhas em praias do litoral da Paraíba, Brasil. Paraíba. 43p. (Monografia de Conclusão de Curso. Centro de Ciências Biológicas, UFPB).

BRASIL 1997. Parâmetros curriculares nacionais: introdução aos parâmetros curriculares nacionais. Secretaria de Educação Fundamental. Brasília: MEC/SEF. 126p.

BRUNO, G. S \& SANTOS, J. L. 2011. Análise qualitativa dos detritos acumulados na praia do Cuiúba, Guarujá, SP. Rev. Ceciliana. 3(2): 4448, Disponível em <http://www.unisanta.br/ revistaceciliana $>$. Acesso em: 20 mar 2018.

FERNANDO DE NORONHA. 2018. Decreto Distrital $\mathrm{n}^{\circ}$ 002, de 12 de dezembro de 2018. Fernando de Noronha, PE. Dispõe sobre a proibição de entrada, comercialização e uso de recipientes e embalagens descartáveis de material plástico ou similares no Distrito Estadual de Fernando de Noronha. Disponível em: $\quad<$ http://www.noronha.pe.gov.br/ instLegislacao.php?cat $=3>$. Acesso em 7 mar 2021.

GLOBAL GARBAGE. 2010. Avaliação da percepção sobre lixo marinho: ferramenta para a gestão do problema. Disponível em: < $<$ https:// www.globalgarbage.org/>. Acesso em 12 mar 2021.

GRANZIERA M. L. \& GONÇALVES A. 2012. Os problemas da zona costeira no Brasil e no mundo. Editora Universitária Leopoldianum. Santos, 316p.

IBGE, 2020. Estimativa da População - 2020. Disponível em: <https://www.ibge.gov.br/>. Acesso em 2 mar 2020

IPOJUCA. 2008. Plano Integrado de Resíduos Sólidos Urbanos do Município de Ipojuca Região Metropolitana do Recife. Termo de Referência 01. Secretaria Estadual do Turismo. Disponível em: <http:// www.todomundofazparte.pe.gov.br/images/ media/IPOJUCA---LEI-1490-2008-planodiretor-EMENTA-.pdf $>$. Acesso em 7 mar de 2021.

IPOJUCA. 2014. Mutirão realiza limpeza na orla de Porto de Galinhas. Disponível em: $<$ www.ipojuca.pe.gov.br/noticias/1297/ mutirao-realiza-limpeza-na-orla-de-porto-degalinhas/> Acesso em: 10 nov 2016.

ICMBio - INSTITUTO CHICO MENDES DE CONSERVAÇÃO DA BIODIVERSIDADE. 2017. Plano de Ação Nacional para a Conservação das Tartarugas Marinhas. Brasília.

IUCN. 2015. Red List of Threatened Species. Disponível em <http://www.iucnredlist.org >. Acesso em: 05 set 2015.

JACOBI, P. 2003. Educação Ambiental, Cidadania e Sustentabilidade. Cad. Pesq., 18: 189205.

JACOBI, P. 2006. Educação Ambiental e o Desafio da Sustentabilidade Socioambiental. Mundo da Saúde. 30: 524-531.

LAIST, D. W. 1987. Overview of the biological effects of lost and discarded plastic debris in the marine environment. Mar. Pollut.Bull. 18: 319-326.

LAIST, D. W. 1997. Impacts of marine debris: Entanglement of marine life in marine debris including a comprehensive list of species with entanglement and ingestion records. In: COE, J. M. \& ROGERS, D. B. (eds.) Marine Debris: Source, Impacts and Solutions. Spring Series on Environmental Management, SpringVerlag: Press, New York, 99-139p. 
LIMA C. S. 2006. Desenvolvimento Local e Turismo no Polo de Porto de Galinhas - PE. Brasília. 126p. (Dissertação de Mestrado. Arquitetura e Urbanismo, UNB).

MAILES NETO, A. 2019. Os canudos plásticos e suas políticas públicas de regulamentação nos países americanos. Rio de Janeiro. 93p. (Projeto de Graduação. Curso de Engenharia Ambiental da Escola Politécnica, UFRJ).

MASCARENHAS, R., BATISTA, C. P., MOURA, I. F., CALCADAS, A. R., COSTA NETO, J. M, VASCONCELOS, M. Q., ROSA, S. S. \& BARROS, .V. S. D. 2008. Lixo marinho em áreas de reprodução de tartarugas marinhas no Estado da Paraíba (Nordeste do Brasil). Rev. Gest. Cost. Integ. 8:221-231.

MENDONÇA, R. 2007. Educação Ambiental Vivencial. In: FERRARO JÚNIOR, L. A. (org.). Encontros e Caminhos: Formação de Educadores Ambientais e Coletivos Educadores. Brasília: MMA, Dir. Edu. Ambie.. 2: 116-129.

ME - MINISTÉRIO DA EDUCAÇÃO. 2001. Parâmetros Curriculares Nacionais: Terceiro e Quarto Ciclos do Ensino Fundamental/ Secretaria de Educação Fundamental - Brasília / SJC: MEC/ SEF/ Univap. 3: 274-279.

MOURA, C. C. M, GUIMARÃES, E. S., MOURA, G. J. B., AMARAL, G. J. A. \& SILVA, A. C. 2012 Distribuição espaço-temporal e sucesso reprodutivo de Eretmochely imbricata nas praias do Ipojuca, Pernambuco, Brasil. Iheringia, Sér. Zool. 102:254-260.

ONU. 2008. Status of the United Nations Convention on the Law of the Sea, em 16 de julho de 2008. Disponível em: <https:// www.un.org/Depts/los/reference_files/ status2008.pdf >. Acesso em: 10 ago. 2008.

ORLANDI N., ARANTES V. \& BARRELLA, W. 2015. Os resíduos sólidos encontrados na praia de Santos - SP. Unis. BioScience. 4: 8389.

ORMEDILLA, A. C., PEREIRA, T. B., MONTEIRO, M. Z. \& MARANHO, A. 2014. Análise dos resíduos antrópicos encontrados no trato digestivo de tartarugas marinhas verdes (Chelonia mydas). Unis. BioScience 3: 8389.

PERNAMBUCO. 2018. Secretaria das Cidades.
Plano de resíduos sólidos: Região de Desenvolvimento Metropolitana de Pernambuco RDM/PE / Secretaria das Cidades. - 2. ed. Recife: Caruso Jr., 108 p. : il.

PIANOWSKI, F. 1997. Resíduos sólidos e esférulas plásticas nas praias do Rio Grande do Sul - Brasil. Rio Grande do Sul. 76p. (Monografia de Graduação, Curso de Biologia, FUFRG).

REIGOTA, M. 2010. Meio Ambiente e Representação Social. $8^{\circ}$ Edição, São Paulo: Cortez, 93p.

REIS, E. C., PEREIRA, C. S., RODRIGUES, D. P. SECCO, H. K. C., LIMA, L. M. RENNO, B \& SICILIANO, S. 2010. Condição de saúde de tartarugas marinhas do litoral centro-norte do estado do Rio de Janeiro, Brasil: Avaliação sobre a presença de agentes bacterianos, fibropapilomatose e interação com resíduos antropogênicos. Oecol. Aust. 14:756-765.

SALES, G., GILFONE, B. B. \& MAURUTTO, G. 2003. Captura incidental de tartarugas marinhas pela frota de rede de emalhe de deriva sediada em Ubatuba, São Paulo - Brasil. Disponível em: <www.tamar.org.br/ publicacoes html/ pdf/2003/2003 Captura Incidental de Ta rtarugas.pdf $>$. Acesso em: 2 mar 2018.

SANCHES, T. M. 1999. Tartarugas marinhas Projeto TAMAR Disponível em: <http:// www.anp.gov.br/meio/guias/sismica/refere/ tartarugas.pdf $>$. Acesso em: 2 mar 2018.

SANTOS, J. G. \& CANDIDO, G. A. 2015. Geração e manejo dos resíduos sólidos resultante das atividades turísticas de Porto de Galinhas. Rev. Brasil. Pesq. Turis., 9: 40-58.

SCHNEIDER, T. 2009 Pesca-fantasma nos mares. Ciência Hoje, 43(257): 62-63 Disponível em: <www.globalgarbage.org/pescafantasma nos mares.pdf $>$. Acesso em: 3 mar 2018.

SIMÕES, T. N., SILVA, A. C., SANTOS, E. M. \& CHAGAS, C. A.. 2014. Temperatura de Incubação e Razão Social em Filhotes recémeclodidos da Tartaruga Marinha Eretmochely imbricata (Linnaeus, 1766) no município de Ipojuca, Pernambuco, Brasil. Pap. Avulsos Zool. 54:363:374.

SIMÕES, T. N., SILVA, A. C., BARBOSA, M. P., 
GUIMARÃES, E. S., LIMA, C. S., SANTOS, E. M. CORREIA, J. M. S. \& MOURA, G. J. B. 2016. Ecoassociados e História de conservação das tartarugas marinhas em Pernambuco. In.: CORREIA, J. M. S., SANTOS, E. M. \& MOURA, G. J. B. Conservação de tartarugas marinhas no Nordeste do Brasil: pesquisas, desafios e perspectivas. Editora Universitária da UFRPE, Recife, 141-144.

SOUZA, D. T. M. T. O, SIMÕES, T. N., SILVA, A. C. \& SANTOS, E. M. 2015. Estratégia de conservação para as tartarugas marinhas - Produção de ferramentas didáticas e ações educativas no litoral de Pernambuco In: SEABRA, G. TERRA. Saúde Ambiental e Soberania Alimentar.1 ed. Ituiutaba. 3: 1318-1328.

SCHUYLER, Q., HARDESTY, B. D., WILCOX, C. \& TOWNSEND, K. 2012. To eat or not to eat? Debris selectivity by marine turtles. PLoS ONE, 7(7): e40884. <https:// doi.org/10.1371/journal.pone.0040884>

SCHUYLER, Q., HARDESTY, B. D., WILCOX, C. \& TOWNSEND, K. 2014. Global Analysis of Anthropogenic Debris Ingestion by Sea Turtles. Conserv. Biol, 28: 129-139.

SUASSUNA, D. A. 2004. Educação Ambiental e o Projeto Tamar. Ambiente e Educação, Rio Grande - Rev. Educ. Ambien. 9: 55-67.

SUL, J.A.I. 2005. Lixo Marinho na Área de desova de Tartarugas Marinhas do Litoral Norte da Bahia: consequências para o meio ambiente e moradores locais. Disponível em: < http://www.agenciacosteira.org.br/ downloads/artigos/ Monografia Juliana Ivar do Sull.pdf >. Acesso em: 3 mar 2018.

YOSHIDA, E. T. E. 2012 Avaliação da influência da ingestão do lixo plástico nos indicadores de estresse oxidativo no sangue de tartarugas verdes (Chelonia mydas). Santa Catarina, 94p. (Dissertação de Mestrado. Centro de Ciências Biológicas, UFSC).

WORLD ANIMAL PROTECTION. 2018. Pesca fantasma pode impactar 69.000 animais marinhos por dia no Brasil. Disponível em: $<$ http://twixar.me/VgKn>. Acesso em: $12 \mathrm{abr}$ 2019. 